\title{
Evaluation of Staging at Diagnosis and Its Relationship with Survival Duration in Nonsmall Cell Lung Cancer Cases in Southern India
}

\author{
Anirban Chakraborty ${ }^{4}$ \\ ${ }^{1}$ Department of Pulmonary Medicine, K.S. Hegde Medical Academy, \\ Deralakatte, Mangalore, Karnataka, India \\ 2Department of Medical Oncology, K.S. Hegde Medical Academy, \\ Deralakatte, Mangalore, Karnataka, India \\ ${ }^{3}$ Department of Community Medicine, K.S. Hegde Medical \\ Academy, Deralakatte, Mangalore, Karnataka, India \\ ${ }^{4}$ Centre for Science Education and Research, Nitte (Deemed to be \\ University), Deralakatte, Mangalore, Karnataka, India
}

Giridhar Belur Hosmane ${ }^{1}$ Rajesh Venkataram¹ Vijith Shetty ${ }^{2} \quad$ Ankeeta Menona Jacob ${ }^{3}$

\begin{abstract}
Address for correspondence Giridhar Belur Hosmane, MBBS, MD, Department of Pulmonary Medicine, K.S. Hegde Medical Academy, Deralakatte, Mangalore 575018, Karnataka, India (e-mail: giridhar.belur@gmail.com).
\end{abstract}

J Health Allied Sci NU:2020;10:63-67

\begin{abstract}
Introduction Lung cancer is one of the most common forms of malignancies worldwide. It is usually diagnosed in late stages due to overlapping symptoms with other respiratory illnesses. Identifying the stage at presentation to tertiary care determines the prognosis of a patient to large extent.

Methods Histologically/cytologically confirmed cases of nonsmall cell lung cancer subjects were included for prospective observational study. Stages of the disease at presentation and survival duration in the patients were studied and the data were compared between two groups: those that accepted and those that refused standard treatment.

Results Ninety-two percent of our patients presented either stage IIIB or stage IV disease at the time of diagnosis. Median duration of survival in the group that took standard treatment was 6 months, whereas in the group that refused standard treat-

Keywords

- lung cancer

- palliative care

- survival duration ment, it was 4 months. Based on their smoking status, the median duration of survival was 4 months among smokers, whereas it was 9 months among nonsmokers with a log rank test value of 3.040 and an insignificant $p$-value of 0.081 .

Conclusion More than $90 \%$ patients presented in later stages of the disease and there was no survival benefit in patients who were treated with palliative care.
\end{abstract}

\section{Introduction}

Lung cancer is one of the most widespread malignancies worldwide. In India, it is the most common cancer among men, accounting for $11.3 \%$ of all new cancers. It is also the most common cause of cancer-related death, constituting $13.7 \%$ of all deaths linked to cancer. ${ }^{1}$ Consistent with the global trend, adenocarcinoma subtype has replaced squamous cell carcinoma as the most common subtype in India. ${ }^{2}$ The data with respect to histological subtype, smoking profile, and stage of the disease at diagnosis show variable trends according to the geographical locations in India. ${ }^{3}$ More than $90 \%$ of nonsmall cell lung cancers (NSCLC) in India are diagnosed beyond stage IIIB, when they are virtually inoperable. At this stage, only options left for treatment are palliative and supportive care, which include chemo and radiotherapy. With the adenocarcinoma subvariety showing a steady increase in India, a large chunk of lung cancer patients shows malignant pleural effusion at the time of seeking health care support. In this study, we have attempted to analyze the stage at diagnosis 
and survival pattern in subjects of NSCLC in Southern India. Such studies have not been reported so far.

\section{Methods}

\section{Objectives and Study Design}

The study was aimed at assessing clinical pattern of NSCLC patients in tertiary care. Primary objectives of the study were to profile the stage of disease at the time of presentation to tertiary care center, to record the survival duration, and compare the data between patients who opt for palliative care and those who refuse. Secondary objective was assessing the survival pattern between smoker and nonsmoker NSCLC subjects. The design of the study was categorized as a prospective observational study conducted in tertiary care teaching hospital in Southern India.

\section{Study Subjects}

Patients who were confirmed to have NSCLC based on histological/cytological evaluation and who were willing to be part of the study were included after obtaining written informed consent. A total of 40 patients were enrolled in the study. The patients were divided in two groups: group I that accepted standard treatment and group II that refused treatment.

\section{Staging}

Enrolled patients were evaluated with computed tomography scan, bronchoscopy, pleuroscopy, and positron emission tomography scans or any other tests as part of standard treatment protocol to confirm stage of the disease. Post diagnosis, further treatment was supervised by medical oncologist and patients were followed up for a period of 2 years from the time of diagnosis.

\section{Study Duration}

The study was conducted for 3 years from August 2016 to July 2019 and all consenting adult NSCLC patients were recruited with a mean follow-up period of 24 months.

\section{Statistical Analysis}

The data were analyzed using SPSS software version 20.0. Descriptive statistics including age, gender, treatment choice, stage, smoking status, and time-to-event and survival rates were collected for individuals in each group. Qualitative variables namely gender, treatment choice, stage, and smoking status were expressed as frequency and proportions. Quantitative variables including age, stage, and time-to-event were expressed as median with 95\% confidence interval. Survival analysis for both the groups was done using Kaplan-Meir curve and log rank test was used to compare the survival rates in both the groups. $p$-Value $<0.05$ was considered to be statistically significant.

\section{Results}

\section{Age, Gender, and Smoking Status}

Of the 40 patients enrolled in the study, 17 were lost during follow-up. Thus, 23 patients were followed up, which comprised of 16 male patients and 7 female patients (-Table $\mathbf{1}$ ). The age at presentation was $>45$ years for the majority of the patients. However, 4 of 23 patients (17.3\%) were less than 45 years of age. Of the 23 patients, 14 were smokers and 9 were nonsmokers.

\section{Stage at Diagnosis}

Twenty-one of the 23 patients (91.3\%) presented in late stages (stage IIIB and stage IV), whereas the remaining two patients presented at stage IIIA. None of the patients were below the stage III at diagnosis.

\section{Treatment Regimen}

Seventeen patients opted for standard treatment as per the advice of oncology team, which was primarily palliative care, consisting of chemotherapy or radiotherapy or both, based on the eligibility of the individual subjects. Six patients refused standard treatment and some of them opted for alternative medicines like Ayurveda and herbal formulations. Three patients were alive in the group that took standard treatment and none were alive in the treatment refusal group at the end of follow-up period.

\section{Statistical Analysis}

Median duration ( - Table 2) of survival in the group that took standard treatment was 6 months (range: 2-10 months),

Table 1 Sociodemographic characteristics of the study population

\begin{tabular}{|c|c|c|c|c|c|}
\hline \multicolumn{2}{|c|}{ Characteristics } & \multirow{2}{*}{ 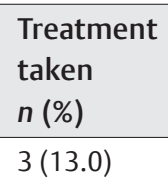 } & \multirow{2}{*}{$\begin{array}{l}\begin{array}{l}\text { Treatment } \\
\text { refusal } \\
\boldsymbol{n}(\%)\end{array} \\
1(4.3)\end{array}$} & \multirow{2}{*}{$\begin{array}{l}\text { Table value } \\
-\end{array}$} & \multirow{2}{*}{$\begin{array}{l}p \text {-Value } \\
-\end{array}$} \\
\hline \multirow[t]{3}{*}{ Age group (y) } & $\leq 44$ & & & & \\
\hline & $45-60$ & $8(34.8)$ & $0(0.0)$ & & \\
\hline & $\geq 61$ & $6(26.1)$ & $5(21.7)$ & & \\
\hline \multirow[t]{2}{*}{ Sex } & Male $(n=17)$ & $12(52.2)$ & $4(21.7)$ & \multirow[t]{2}{*}{0.032} & \multirow[t]{2}{*}{0.618} \\
\hline & Female $(n=6)$ & $5(17.4)$ & $2(8.7)$ & & \\
\hline \multirow[t]{2}{*}{ Smoking } & Current smoking & $10(43.5)$ & $4(17.4)$ & \multirow[t]{2}{*}{0.115} & \multirow[t]{2}{*}{0.565} \\
\hline & No/past smoking & $7(30.4)$ & $2(8.7)$ & & \\
\hline \multirow[t]{2}{*}{ Event } & Alive & $3(13.0)$ & $0(0.0)$ & \multirow[t]{2}{*}{1.218} & \multirow[t]{2}{*}{0.384} \\
\hline & Death & 14 (60.9) & $6(26.1)$ & & \\
\hline
\end{tabular}


Table 2 Median survival among individuals

\begin{tabular}{|l|l|l|l|}
\hline Group & $\begin{array}{l}\text { Median }(95 \% \mathrm{Cl}) \\
\text { in months }\end{array}$ & $\begin{array}{l}\text { Log rank } \\
\text { test value }\end{array}$ & $p$-Value \\
\cline { 1 - 3 } $\begin{array}{l}\text { Standard treatment } \\
\text { of NSCLC }\end{array}$ & $6(2.0-10)$ & 0.782 & 0.376 \\
\cline { 1 - 2 } $\begin{array}{l}\text { Refused treatment } \\
\text { for NSCLC }\end{array}$ & $4(3.5-4.4)$ & & \\
\hline
\end{tabular}

Abbreviations: $\mathrm{Cl}$, confidence interval; NSCLC, nonsmall cell lung cancer.
Table 3 Median survival among individuals based on smoking status

\begin{tabular}{|l|l|l|l|}
\hline Group & $\begin{array}{l}\text { Median }(95 \% \mathrm{Cl}) \\
\text { in months }\end{array}$ & $\begin{array}{l}\text { Log rank } \\
\text { test value }\end{array}$ & $p$-Value \\
\cline { 1 - 2 } $\begin{array}{l}\text { NSCLC patients with } \\
\text { current smoking }\end{array}$ & $4(3.3-4.7)$ & 3.040 & 0.081 \\
\cline { 1 - 2 } $\begin{array}{l}\text { NSCLC patients } \\
\text { with no/past smoking }\end{array}$ & $9(6.1-11.9)$ & & \\
\hline
\end{tabular}

Abbreviations: $\mathrm{Cl}$, confidence interval; NSCLC, nonsmall cell lung cancer.

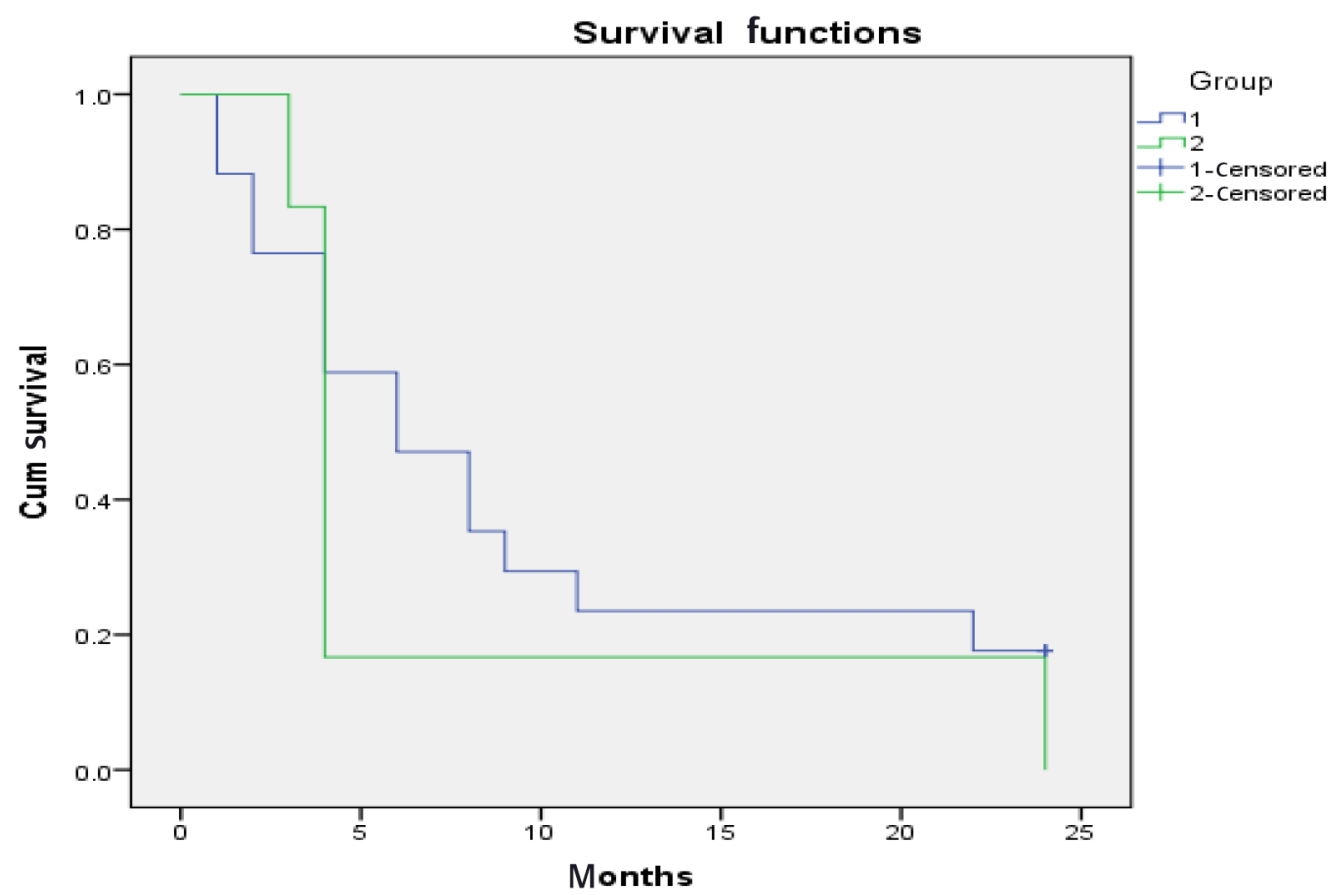

Fig. 1 Kaplan-Meir curve for the two groups: Group 1, standard palliative treatment; Group 2, refused palliative treatment.

whereas in the group that refused standard treatment, it was 4 months (range: 3.5-4.4 months) with a log rank test value of 0.782 and $p$-value of 0.376 (-Fig. 1).

The comparison of the median duration of survival on the basis of their smoking status revealed that smokers had a median duration of survival (- Table 3 ) of 4 months (range: 3.3-4.7 months), whereas it was 9 months among nonsmokers (range: 6.1-11.9 months) with a log rank test value of 3.040 and an insignificant $p$-value of 0.081 (-Fig. 2).

\section{Discussion}

The stage at the time of diagnosis is the most important factor in determining length of survival of NSCLC patients. ${ }^{4}$ Although surgically amenable lung cancer patients have the best survival chance, those treated with conventional chemo-radiotherapy do not show any significant survival benefit. However, improvement in symptom profile and quality of life has been documented. In our study, majority (92\%) of our subjects (21 among 23 subjects) were diagnosed in the stage
IIIB and beyond, when only palliative care is the treatment option available.

Among 40 patients, 17 were lost to follow-up after initial diagnosis of malignancy was confirmed. They did not make any further visits to hospital including staging of the malignancy. This loss in follow-up (42.5\%) could be due to the stigma of malignancy that is still prevalent in India, due to poorer economic condition. Once diagnosis of malignancy is made, patients not only hesitate to spend any further but also approach traditional healing methods such as Ayurveda, siddha- or plant-based medicines.

In India, lung cancer is generally diagnosed at late stages and the reasons could be many. General awareness about cancers in India is very poor and patients seek health care support quite late in the course of the disease. ${ }^{5}$ India is still an endemic for tuberculosis and symptoms of lung cancer, which overlaps with pulmonary tuberculosis (PTB) and other lung conditions, often gets overlooked or delayed. PTB is diagnosed and treated under National Tuberculosis Elimination Program (NTEP), in which discretion to start antitubercular 


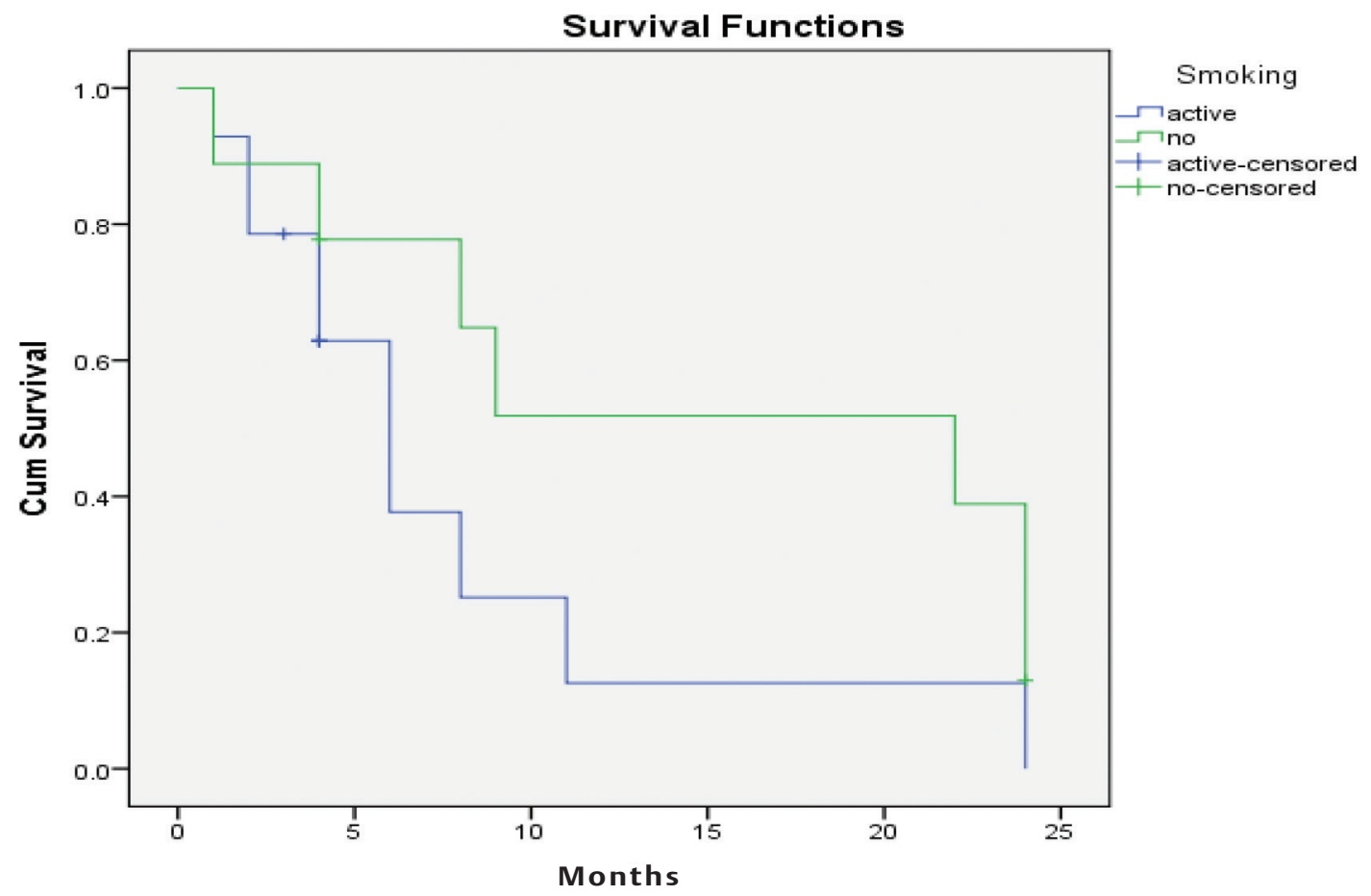

Fig. 2 Cumulative survival and smoking status.

treatment is based on radiological appearances in certain clinical settings.

A previous study has suggested the early use of invasive diagnostic tools to establish diagnosis of lung cancer in geographical areas where PTB is endemic. ${ }^{6}$ Smoking has been the single most important risk factor behind both lung cancer and chronic obstructive pulmonary disease (COPD). Symptoms such as breathlessness, cough, and hemoptysis exist in both diseases, leading to delayed diagnosis of lung cancer in pre-existing COPD. Hong et $\mathrm{al}^{7}$ have concluded that hazards of death from lung cancer are significantly increased in cases with pre-existing lung disease, and worsen with longer durations, and with multiple combinations before cancer diagnosis. Patients and physicians should be aware of these risk/prognostic factors for lung cancer when identifying high-risk patient groups. ${ }^{7}$ Despite increasing efforts toward creating awareness, women in India generally seek medical care very late in the course of the disease. For instance, a study on breast cancer in women in India revealed that they approach health care very late, which is partly related to sociodemographic profile and belief in traditional medicine. ${ }^{8}$ Thus, there is a pertinent need to improve the awareness about symptoms of cancer, to reduce misdiagnosis of lung cancer as PTB, to have high index of suspicion among patients with pre-existing lung diseases, particularly, COPD, and the sociocultural issues of women not seeking care early in the disease.

In our study, we observed there was no survival benefit among group of subjects who were treated with palliative care and group of patients who refused palliative care. This is consistent with the trends across the globe; palliative care only improves symptom free survival and quality of life; however, it provides no benefit on survival duration. ${ }^{9}$

Multiple studies have documented improved prognosis and better overall survival in nonsmoking NSCLC patients. Indeed, in our study, the median survival among NSCLC patients who are/were smokers was 4 months with range of 3.3 to 4.7 months, whereas in nonsmoker NSCLC group, it was 9 months with range of 6.1 to 11.9 months. However, we could not find any significant statistical correlation between smoking status and duration of survival. An earlier study has demonstrated that ever-smokers had poorer survival rates than never-smokers, and current smoking was a significant prognostic factor of a poor prognosis in the study population. ${ }^{10}$ Similarly, another study by Clément-Duchêne et $\mathrm{al}^{11}$ opined that improved survival in nonsmokers was probably related to factors like female gender, Asian race, and higher incidence of adenocarcinoma. ${ }^{11}$ In a review on "lung cancer in never smokers" by Subramanian and Govindan, ${ }^{12}$ it has been shown that adenocarcinoma is the predominant subtype and improved response rates to epidermal growth factor receptor-tyrosine kinase inhibitors ${ }^{12}$ like gefitinib and erlotinib in nonsmokers.

\section{Conclusion}

In our study, it was quite evident that the majority of subjects had presented at later stages of disease. There were no survival benefits between patients who opted for palliative treatment and those who refused. In addition, there was no significant survival difference between smoking and nonsmoking NSCLC subjects. Thus, early and 
accurate diagnosis of lung malignancies, regardless of the smoking status and gender, could significantly enhance the survivability of the patients. In a country like ours, where the majority of the population is deprived of quality health care, creating awareness among the people, particularly among those at risk, could be crucial in the effective management of lung cancer cases and in improving the survival duration post-treatment.

\section{Conflict of Interest}

None declared.

\section{References}

1 Behera D. Lung cancer in India: challenges and perspectives. J Thorac Oncol. 2017;12(1(supplement)):S114-S115

2 Kaur H, Sehgal IS, Bal A, et al. Evolving epidemiology of lung cancer in India: reducing non-small cell lung cancer-not otherwise specified and quantifying tobacco smoke exposure are the key. Indian J Cancer 2017;54(1):285-290

3 Singh N, Behera D. Lung cancer epidemiology and clinical profile in North India: similarities and differences with other geographical regions of India. Indian J Cancer 2013;50(4):291

4 Detterbeck FC, Boffa DJ, Tanoue LT. The new lung cancer staging system. Chest 2009;136(1):260-271
5 Raj S, Piang LK, Nair KS, Tiwari VK, Kaur H, Singh B. Awareness regarding risk factors, symptoms and treatment facilities for cancer in selected states of India. Asian Pac J Cancer Prev 2012;13(8):4057-4062

6 Chen C-Y, Wang J-Y, Chien Y-C, Chen K-Y, Yu C-J, Yang P-C. Lung cancer mimicking pulmonary tuberculosis in a TB-endemic country: the role of early invasive diagnostic procedures. Lung Cancer Manag 2015;4(1):1310.2217/lmt.14.46

7 Hong S, Park EC, Kim TH, et al. Effect of pre existing respiratory conditions on survival of lung cancer patients: a nationwide population-based cohort study. Asia Pac J Clin Oncol 2018; 14(2):e71-e80

8 Pakseresht S, Ingle GK, Garg S, Sarafraz N. Stage at diagnosis and delay in seeking medical care among women with breast cancer, Delhi, India. Iran Red Crescent Med J 2014;16(12):e14490

9 Farbicka P, Nowicki A. Palliative care in patients with lung cancer. Contemp Oncol (Pozn) 2013;17(3):238-245

10 Lee SJ, Lee J, Park YS, et al. Impact of smoking on mortality of patients with non-small cell lung cancer. Thorac Cancer 2014;5(1):43-49

11 Clément-Duchêne C, Stock S, Xu X, et al. Survival among never-smokers with lung cancer in the cancer care outcomes research and surveillance study. Ann Am Thorac Soc 2016;13(1): 58-66

12 Subramanian J, Govindan R. Lung cancer in never smokers: a review. J Clin Oncol 2007;25(5):561-570 